International Journal of English Literature and Social Sciences
Vol-6, Issue-3; May-Jun, 2021
Journal Home Page Available: https://ijels.com/
Journal DOI: $10.22161 /$ ijels
Peer-Reviewed Journal

\title{
Distant Learning in Morocco: Examining Students' Attitudes and Motivation at the Tertiary Level
}

\author{
Rachid Elkhayma
}

Laboratory of Language and Society, Ibn Tofail University, Kenitra, Morocco

Received: 29 Jan 2021; Received in revised form: 21 Mar 2021; Accepted: 15 Apr 2021; Available online: 10 May 2021

C2021 The Author(s). Published by Infogain Publication. This is an open access article under the CC BY license

(https://creativecommons.org/licenses/by/4.0/).

\begin{abstract}
The outbreak of Covid-19 has unprecedentedly evinced that online learning is the future of education. It offers abundant benefits and poses various challenges to learners and teachers alike. Some of these challenges represent the extent to which students are willing to take part in these classes, and how instructors and teachers can help them increase their motivation and develop positive attitudes towards their distant classes, the teachers and the course at large. In this context, this study empirically examines Moroccan students' motivation for and attitudes towards online learning, and seeks to find practical techniques to improve their level of motivation and gain constructive perceptions of e-learning at large. The study adopts a predominantly quantitative method that makes use of 89online questionnaires distributed to students from the Faculty of Languages and Arts in Ibn Tofail University. The findings revealed that the majority of students hold negative attitudes towards distant learning, which makes them lose motivation for these classes.
\end{abstract}

Keywords - Distant learning, attitudes, motivation, Moroccan students, university level.

\section{THEORETICAL FRAMEWORK}

\subsection{Introduction}

The spread of the new Corona Virus forced schools around the globe to close down. It was an untimely event to start ${ }^{1}$ distant education in Morocco. Although initial logistics were unsatisfying, things started to upgrade. Instead of WhatsApp and Facebook, teachers used online platforms to reach out to their students. They met via Zoom, Google Classrooms and other video communication tools.

Since it was a new educational experience, challenges began to come out; from weak internet network speed and lack of e-learning equipment to students' learning-related issues such as negative attitudes towards online classes and lack of participation and motivation. In the midst of all of this, the process continued wherein the teachers had to look for ways to meet students' expectations by designing new online content and by embarking on new teaching methods and modalities.

The distant learning and teaching setting has spawned a variety of bundles and bungles among students and teachers alike. Despite the outstanding efforts university professors have been making, a lot of students may still be displeased with the new distant educational experience that they have been trying to approach. Many of them complained about the inability to attend and connect to classes, understand the content and follow the fast course pace. It is also noticeable that a lot of others have been running into several difficulties such as lack of motivation and participation, along with preconceived perceptions of online education inefficacy compared to the proximate one.

1The terms distant learning, online learning, virtual learning, e-learning are used interchangeably in this study.

\subsection{Definitions of online education}

Distant education appeared in 1890 when William Harper first set up the primary American distance communication project between teachers and students staying in different locations (Gunawardena \& McIsaac, 2004). Distant education refers to the use of information and communication technologies to teach students from 
another location. It incorporates various pedagogical methods that can possibly help students learn in such a distant environment. It is a sort of education that involves the Internet and new digital technologies with the intention of improving new learning opportunities or replacing the existing ones that are performed in conventional face-toface settings.

In addition, Distant education, which involves the technological separation of the teacher and the student, necessitates their presence in "a fixed place (school, college, university) at a fixed time (school timetable, training schedule, lecture programme), to meet a fixed person (teacher, instructor, professor) in order to be trained or educated" (Keegan, 1995).With this type of education, students are able to pursue a remotely-based learning system, and have access to various study content that is at their disposal whenever they want and wherever they are. That implies they can learn at their own pace using the material they have or that is provided to them.

Following Taylor (2001), distant education evolved over time in four different generations. The first generation was 'the correspondence Model' that used print technology. The second one was the 'Multimedia Model' that capitalized on print, audio and video. The third generation was represented by the 'Tele-learning Model' that incorporated" applications of telecommunications technologies to provide opportunities for synchronous communication" (p. 2). In the fourth generation, there was the 'Flexible Learning Model' that was based on online communication by way of the Internet. Currently, the fifth generation has already emerged, and it capitalizes on the features of the fourth generation; that is on the Internet and the World Wide Web.

Researchers have pinned down several characteristics of distant education. The first one involves the physical dissociation of the teachers and learners (Gunawardena \& McIsaac, 2004; Keegan, 1995 \& 2000). The second feature is the presence of an individualized process in which learning is likely to take place at an individual level (Keegan, 1995; Joseph, 2005); however, the teacher can also deal with students in groups. Another characteristic is the application of the multiple venues that are related to and encouraged by the rapid spread and growth of information technology, the Internet and social media outlets, such as Zoom, Google Classroom, Microsoft Teams, Facebook, WhatsApp, and so on and so forth.The fourth characteristic centers around the use of communication and technology-based tools and techniques (phones, computers, video conferencing, etc.) to establish connection between the parties involved in online classrooms.
By and large, the variations attached to distant education are obviously far removed from those of proximate education, but it is important to note that as ebooks cannot replace paper books, digital means cannot replace the genuineness and proximity of face-to-face education. However, online learning can still be more accessible and doable as long as the student and teacher have digital devices and stable internet connection albeit when and where they are. Therefore, its accessibility is the main reason why it is deemed practical and time and effort saving.

\subsection{Benefits of online learning}

Online classes encompass a variety of benefits. They allow learners and teachers to schedule classes according to their learning needs and program depending on how they manage their time. This is actually not possible in proximate education, which necessitates a fixed setting and schedule. Besides, each learner has the chance to study at his / her personal pace. When learning from a distance, there is no need for the student to worry about being a fast or slow learner; the class pace can be tailored according to the individual student's level.

Moreover, online classes allow learning to take place in asynchronous time and place (Johnson, 2008). So learners are not required to abide by particular schedules. Besides, students are able to develop a sense of autonomy and autonomous learning by which they can learn how to reach out to a paucity of online content and information. Moreover, distant learning helps students and teachers in numerous other areas:

- It responds to several learning styles (diversified learning strategies);

- It allows for an increasingly interactive pedagogy;

- It offers good opportunities for dialogue and exchange;

- It allows the development of communication skills;

- It promotes the development of collective, global and complex thinking;

- It promotes access to a group of students through the use of interactive communication tools;

- It allows you to tame technology;

- It reduces racial, ethnic, gender, religious and physical appearance differences;

- It offers greater flexibility and organization to teachers ;

- It requisites a pedagogical and technological flexibility;

- It allows teachers better planning of students' learning; 
- It allows teachers for invariable contact and availability;

- It helps teachers develop greater ICT skills.

\subsection{Weaknesses of online learning}

Despite its many advantages, distant learning has a number of drawbacks. The first one is the lack of direct human contact that is likely to make it hard for some students to achieve better learning results. The existence of so many different learning supports represents another hurdle for those students who may feel lost with the absence of face-to-face pedagogical assistance and adaptation. Also, the other two major deficiencies in distant education are the lack of students' motivation for actively engaging in the online class activities and the minimum interaction and communication opportunities it provides to learners.

In addition to all of these and because of long study hours on their computers, phones or other devices, students may feel tired or be exposed to physical, and even, mental problems. Again, on account of the nature of individualization in distance learning, some learners are likely to harbor a feeling of isolation that will probably later develop into a feeling of remoteness. Last but not least, problems related to discipline, which is practically hard to maintain while studying online, represent other issues that teachers have to constantly face.

\subsection{Motivation for foreign language learning}

Motivation is one of the most conspicuous emotional factors influencing FL learning. Teaching a foreign language involves meeting learners' needs and overcoming the demanding challenge of students' willingness to engage in classroom activities. If learners are not willing to make efforts, the whole process will run into an intricate situation. This shows that motivation or the active participation of the student in a foreign language course, which is often built around communication, represents a big challenge that directly affects learning.

One of the earliest theories that deals with motivation and learning foreign languages is the one developed by the Canadian researchers Gardner and Lambert in 1959. Their theory is based on Mowrer's social behavioral ideas wherein the child learns how to speak by imitating their parents. Mowrer's theory insinuates that "language acquisition is motivated by a desire to be like valued members of the family and, later, of the whole linguistic community" (Gardner \& lambert, 1959, p. 266). This children's tendency to imitate their parents is alluded to by Mowrer as "identification". According to Gardner and Lambert, this identification process is the foundation of a long-term motivation that helps develop a FL competence.
Whilst Gardner and Lambert proposed two forms of motivation (integrative and instrumental), Deci and Ryan (1985) came up with two basic needs for motivation: intrinsic and extrinsic. Integrative motivation is present when the learner wishes to learn a language for integrative motives in the community or group they belong to, and the instrumental form is about learning a language with an intention to achieve certain objectives such as obtaining a profession. In Deci and Ryan's dichotomy, intrinsic motivation takes shape when an individual carries out an activity for the satisfaction he or she finds in it. The commitment is spontaneous and nourished by interest or curiosity. On the other hand, extrinsic motivation stands for engaging in an activity for the purpose of achieving possible rewards associated with it, such as good marks, diplomas, prizes, etc.In the words of Deci and Ryan (1985), it "refers to [a] behavior where the reason for doing it is something other than an interest in the activity itself. Such behavior may, however, to a greater or lesser extent, be something the person feels pressured to do versus genuinely wants to do"(p. 35).

Admittedly, these two motivational behaviours (intrinsic and extrinsic) complement one another, but it is clear that the intrinsic side is the one that has the upper hand on learners' long-term motivation since it is not as dependent on outside factors as extrinsic motivation is.

In the online classroom, student's motivation for learning may originate from any of those needs, be they from a desire to use the language for communicative purposes, professional needs, or for personal goals. And since motivation pushes learners to engage in classroom activities, the teacher is expected to stimulate the development of the intrinsic type, because it has been found that motivation is one of the major factors that "contribute to success in distance learning environments" (Artino, 2008, p. 261). It also plays a decisive role in stimulating students' interests that "can be used to improve learning environments" (Keller, 2008, p. 180). This illustrates that without being motivated, intrinsically and sometimes extrinsically, learners will possibly encounter a substantial difficulty thriving in distant education in general.

\subsection{Attitudes to foreign language learning}

A number of factors influence students' attitudes to foreign language learning. Some are related to the teacher, while others are associated with the school and curriculum (Bartram, 2010).

Students' attitudes towards learning are closely tied to the type of relationship teachers have with them. The more the EFL teacher approaches his / her students, the more they like the language and the teacher as well, 
and if the opposite takes place, then the results may turn counter-productive. Chambers (1999) affirms that "the teacher is named as the reason, for example, why they like/dislike German, why their learning experience has improved/ deteriorated" (as cited in Bartram, 2010, p. 43). Neither methodology nor pedagogy is likely to be as conspicuous as the teacher's role is in alluring learners' hearts and minds. This is why it is purposively recommended that teachers establish a constructive rapport with students by creating welcoming learning settings. This is carried off with the help of a paucity of techniques such as humor, for instance, for it has been found that it "rid[s]students of classroom tension as they became more willing to talk and less anxious about making mistakes" (Elkhayma, 2021, p. 448).

Though less impactful than the teacher's role, pedagogy and methods may still affect students' attitudes towards FL learning in several ways. Communication apprehension or the fear of being unable to engage in language oral activities is one of the reasons why students may feel uncomfortable (Horwitz et al., 1986, as cited in Elkhayma, 2020). This situation comes about when the learner is involved in speaking tasks like open-pair dialogues, but is anxious about making mistakes in front of his / her peers. In her study about boys learning French, Court discovered that learners do not want to look foolish in class or "embarrassed at having to produce strange noises in the presence of girls" (Bartram, 2010, p. 47).

Additionally, students' satisfaction may suffer from the lack of variety and innovation in teaching. As an EFL teacher, I have come across many complaints from students being unhappy with a rigid teaching method or style. They usually like variety in the way teachers approach classroom activities, like diversifying language skills; using communication activities (open /closed-pair dialogues), collaborative activities (sorting, matching, etc.),games, songs and technology; tapping on students' learning styles and preferences, and so for.However, even with the presence of variety, the teacher's role in creating a warmly learning setting is inevitable.

Attitudes are thus important because they predispose the student to either accept learning or disengage fromit.It is up to the teacher then, as part of his / her efforts to constructively modify students' attitudes, to help them develop autonomy, assume more and more responsibility and build up an appropriate environment that is conducive to learning. If learners are able to take charge of their own learning, the process of acquiring greater autonomy will likely induce changes in their attitudes.

\subsection{Some studies about distant education in Morocco}

Several studies were conducted in Morocco to investigate students' perceptions of distant learning.In a study of 741 participants that was carried out by ENSAM Casablanca, it was discovered that 8 out of 10 students are not pleased with and ill-prepared for online education (l'économiste, $\mathrm{n}^{\circ}$ 5753, 04/05/2020; as cited in Ezzahid, 2020). Ezzahid added that only a quarter of the surveyed students were able to comprehend their lessons, and another quarter of them were unable to make sense of the classroom activities.

Aziz Hantem and his team (2020) performed a qualitative study that targeted university students from faculties and higher institutes across the country such as ISCAE, ENCG, OFPPT, etc. The results showed that $83 \%$ of the respondents failed to concentrate on their studies, and were apprehensive about their exams, while $17 \%$ were not influenced by the lockdown situation. The results also revealed that $78 \%$ of the participants conveyed satisfaction with their teachers' involvement and commitment to meet the objectives of distant education. Only $22 \%$ thought that teachers' efforts were insufficient.

In the same regard, a group of researchers teamed up to launch two simultaneous studies that were realized by means of online questionnaires. They found out that 65 $\%$ of the students were generally satisfied with distant learning during the lockdown, and $60 \%$ were capable of adapting to the new learning context.

\section{METHODOLOGY}

The study is basically quantitative. Most of the questions and statements in the 89 questionnaires used by the study as data collection instruments are closed ended, whereas three others are open-ended. The surveys were designed to gather information about students' perceptions of and attitudes towards distant education. More specifically, they aimed at eliciting information about whether students like online learning or not; the extent to which they consider it helpful or unhelpful; whether they have constructive attitudes towards it or negative ones; the extent to which they prefer it to the in-classroom education; and whether they are motivated to engage in distant education.

The questionnaires were completed via Google Doc by S1 English language students enrolled in the Faculty of Languages and Arts, which is part of Ibn Tofail University in Kenitra, Morocco. The sampling strategy by which the target students were selected adopted a convenient sampling technique given their availability for the study and the access that the researcher had to them through emails and online classroom teaching / learning platforms. Moreover, the data obtained from students' 
surveys were analyzed by the SPSS statistical program version 10 .

\section{RESULTS AND DISCUSSION}

Students' attitudes towards distant learning differ from a student to another depending on several social, geographical, educational, psychological and technical factors. It has been discovered that the majority of students hold negative perceptions of distant learning (see tables 1 , $2,3,4,5$, and figures 1,2$)$.In responding to the statement of whether distant learning is the future of education, more than $49.4 \%$ of them disagree with this idea as shown in figure 1 . Less than half of them $(40.4 \%)$ show agreement with the statement provided, while $10 \%$ of the respondents are uncertain about their positions. On account ofa variety of issues, some of which are logistical imperfections (internet network reliability),social disadvantages (poverty among students), or cultural factors such as embracing the belief that traditional education is irreplaceable, many students do not think that distant learning may in any ways overtake the proximate one.

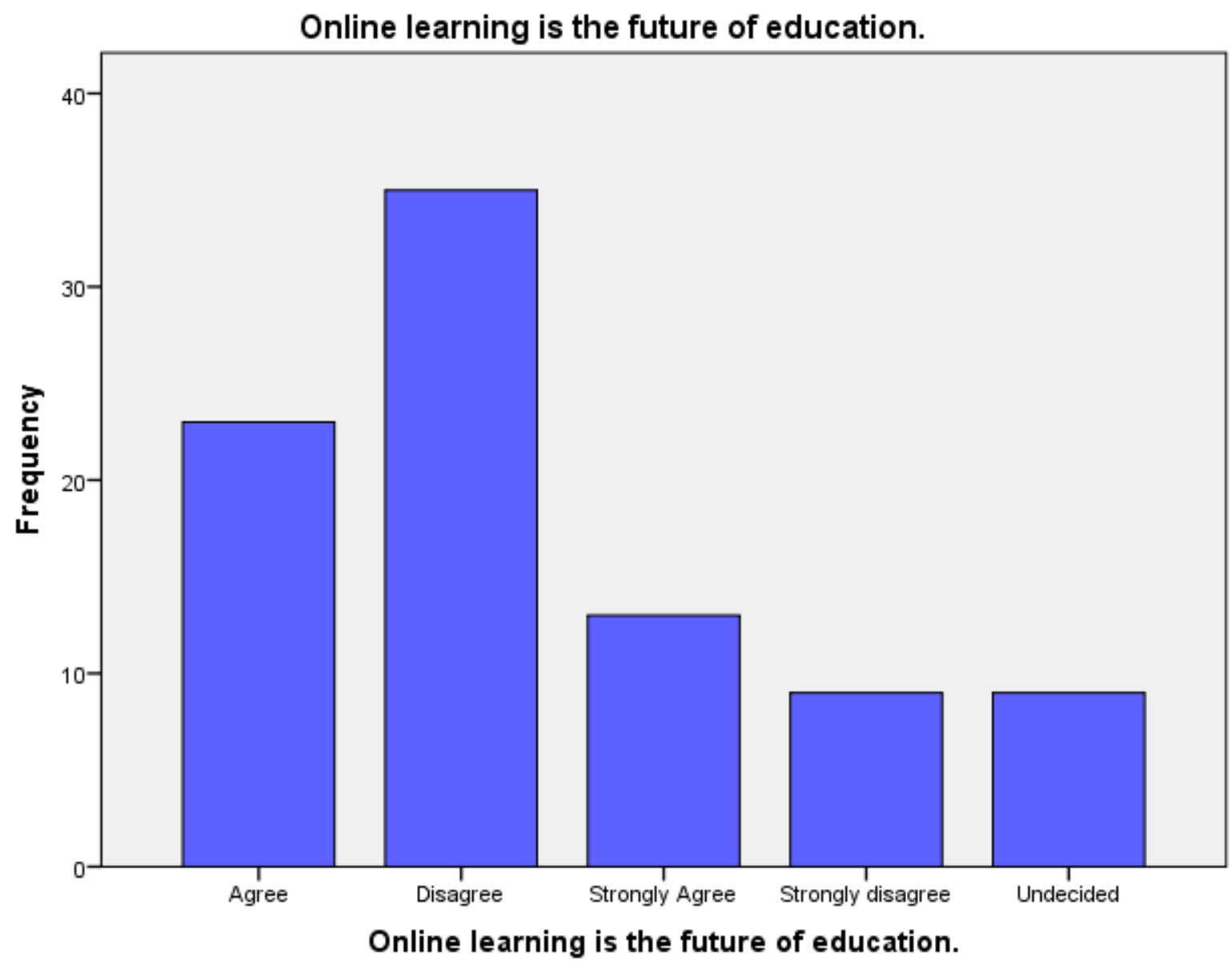

Fig.1: Online learning is the future of education

Students' perceptions of whether online learning is beneficial to them are not unanimously constructive. A lot of them are skeptical about the benefits they can possibly obtain from attending online classes. They appear to be disoriented, not knowing exactly what they may have or have not acquired in class. In this regard, $28.1 \%$ in total express uncertainty about whether they have gained any benefits, and $33.7 \%$ others denied any sort of educational profits. Still, $38.2 \%$ of the respondents, as shown in table
1, unequivocally clarified that these e-learning courses have helped them grasped and developed a substantial amount of information and skills like how to augment concentration, attention and autonomy. This particular attitude corresponds with other opinions wherein many other students $(56.2 \%)$ posit that e-learning cannot replace the in-classroom one; in the sense that they study better in conventional classes.

Table 1: Online learning is beneficial to students 


\begin{tabular}{|c|c|c|c|c|c|}
\hline & & Frequency & Percent & Valid Percent & Cumulative Percent \\
\hline \multirow{4}{*}{ Valid } & Undecided & 25 & 28,1 & 28,1 & 28,1 \\
\hline & No & 30 & 33,7 & 33,7 & 61,8 \\
\hline & Yes & 34 & 38,2 & 38,2 & 100,0 \\
\hline & Total & 89 & 100,0 & 100,0 & \\
\hline
\end{tabular}

By the same token, a great number of students clearly state that they cannot understand better when they study in the virtual platforms. In table 2, their views indicate that they have gone through difficult times being unable to make sense of the lessons and teachers' explanations. Many of them communicate negative ideas towards this matter (39 respondents in table 2), while a few others are not sure if they understand their learning content or not. As for the rest, they convey emboldening attitudes towards using e-learning in the Moroccan education system, and this is exhibited in the relatively increasing number of students (31 respondents in table 2) who appreciate their lessons and who are content with the new online educational venture.

Table 2: Students understand better when they study online

\begin{tabular}{|c|c|c|c|c|c|}
\hline & & Frequency & Percent & Valid Percent & Cumulative Percent \\
\hline \multirow{4}{*}{ Valid } & Undecided & 19 & 21,3 & 21,3 & 21,3 \\
\hline & No & 39 & 43,8 & 43,8 & 65,2 \\
\hline & Yes & 31 & 34,8 & 34,8 & 100,0 \\
\hline & Total & 89 & 100,0 & 100,0 & \\
\hline
\end{tabular}

Likewise, in confirmation of what has been stated so far, more than $48 \%$ of the respondents (see table 3) reiterate their prior position that they cannot learn enough in these classes, because, as one stated, 'not everyone has the Internet and a computer that enables them to follow the lesson comfortably, so I feel that opportunities are unequal, and this is the only negative thing about distance education'. another one added that distant learning 'doesn't help students learn better but it's [sic] just can give you some ideas about the studies you learn, [sic] that's why, [sic] in-classroom learning is much better than online learning'.

Conversely, $36 \%$ of the students affirm their satisfaction with the level of learning they receive as long as that relieves a lot of them from the financial hardship of physically moving to the faculty as illustrated in this student's quote: 'It helps alot! it's[sic] affordable for all students, [sic] we don't have to stop our studies or quit because we can't pay hundreds of dirhams weekly for transportation and rent and stuff like that, [sic] we can attend classes from anywhere'.

Table 3: Students do not learn enough in online classes

\begin{tabular}{|c|c|c|c|c|c|}
\hline & & Frequency & Percent & Valid Percent & Cumulative Percent \\
\hline \multirow{4}{*}{ Valid } & Undecided & 14 & 15,7 & 15,7 & 15,7 \\
\hline & No & 32 & 36,0 & 36,0 & 51,7 \\
\hline & Yes & 43 & 48,3 & 48,3 & 100,0 \\
\hline & Total & 89 & 100,0 & 100,0 & \\
\hline
\end{tabular}

In the same vein, one of the toughest challenges for teachers in distant learning is how to enhance students' motivation and participation. Statistics convey that the majority of students are not enthusiastic about attending their online classes (table 4), and a relatively high number of them are oblivious to the fact that they may or may not possess any sort of motivation for it. 


International Journal of English Literature and Social Sciences
Vol-6, Issue-3; May-Jun, 2021
Journal Home Page Available: https://ijels.com/
Journal DOI: $10.22161 /$ ijels
Peer-Reviewed Journal

Table 4: Students are enthusiastic about attending online classes

\begin{tabular}{|c|c|c|c|c|c|}
\hline & & Frequency & Percent & Valid Percent & Cumulative Percent \\
\hline \multirow{4}{*}{ Valid } & Undeided & 31 & 34,8 & 34,8 & 34,8 \\
\hline & No & 33 & 37,1 & 37,1 & 71,9 \\
\hline & Yes & 25 & 28,1 & 28,1 & 100,0 \\
\hline & Total & 89 & 100,0 & 100,0 & \\
\hline
\end{tabular}

Also, more than half of them do not seem to endorse participation in classroom activities (table5). This implies that boosting participation and motivation is a requisite consideration for success in such unconventional settings, and which can be achieved by claiming the following procedures some of which are based on ELSeoud and Mohamed (2015):

- Keep students attentive and focused by encouraging them to participate, and by allowing them the opportunity to talk so that they do not feel isolated;

- Call individual students each by his / her name to communicate and share opinions;

- Encourage students to be responsible for their learning;

- Praise students individually and in groups to boost their self-esteem and self-confidence;

- The designed content should target the course objectives and meet students' expectations;
- The level of difficulty in the constructed course content should be gradual and measured in order not to frustrate the students right from the outset;

- Use humor devices in the form of verbal and nonverbal gestures to alleviate anxiety and develop their enthusiasm and motivation;

- Encourage students to communicate their enquiries and concerns;

- Inspire students to create study groups in order for them to work collaboratively, not in isolation;

- In scheduling classes, the teacher is expected to consider any technological challenges the students may experience or that may hinder their participation, which is likely to generate demotivation;

- Diversify the course content in a way that taps in different learners' learning styles;

- It is important to establish a warmly learning environment that caters for psychological issues like stress and nervousness.

Table 5: Students participate more in online classes

\begin{tabular}{|c|c|c|c|c|c|}
\hline & & Frequency & Percent & Valid Percent & Cumulative Percent \\
\hline \multirow{4}{*}{ Valid } & Undecided & 21 & 23,6 & 23,6 & 23,6 \\
\hline & No & 34 & 38,2 & 38,2 & 61,8 \\
\hline & Yes & 34 & 38,2 & 38,2 & 100,0 \\
\hline & Total & 89 & 100,0 & 100,0 & \\
\hline
\end{tabular}

By and large, a high number of the participants who appear to have supported distant classes, following their responses, are the ones who live in other cities and towns far from the university. They argue that it is 'practical, time-saving and economical' to study online. They appear to favor geographically distant education to physical proximity as long as they have access to the teacher and study content. According to them, online learning, which they believe to be 'beneficial and not a waste of time', is deemed the 'best solution during this pandemic' as they do not need to take the burden of travelling or commuting to the university.

Nevertheless, most of the participants are fully aware of the importance of online classes during this pandemic. They revealed constructively positive opinions 
(54 out of 89 respondents as communicated in figure 2) that these sorts of classes cannot be a waste of time since we are in extraordinary health circumstances, whereas few others (18 students) are totally unhappy with studying online. This is an indication that there is a common belief among students that these classes can serve real educational purposes as illustrated in these students' responses:

'We provide ourselves with a suitable environment to study (calm, listen and watch clearly)';

'We can participate in the lesson and express as much as we want and without shame';

'We can record the lecture and refer to it later';

'In distance education, we are only interested in studying, not renting, eating or transporting'.
The other category of students who disapprove of online learning are, following their statements, mostly the ones who find it effortlessly accessible tomove to the college classrooms. For some of them, studying online is 'useless', and they can 'learn almost nothing' because they do not fully concentrate. Geographical proximity pushes them to prefer face-to-face classes to the online ones, for they believe they could learn better when the teacher is "by my side", as one explained. For others, they share the same opinion as the majority of students that the biggest dilemma in online classes is internet speed-related problems and the lack of technologically reliable equipment such as smartphones and computers. same attitude as the majority of students that the biggest dilemma in online classes is internet speed-related problems and the lack of technologically reliable equipment such as smartphones and computers.

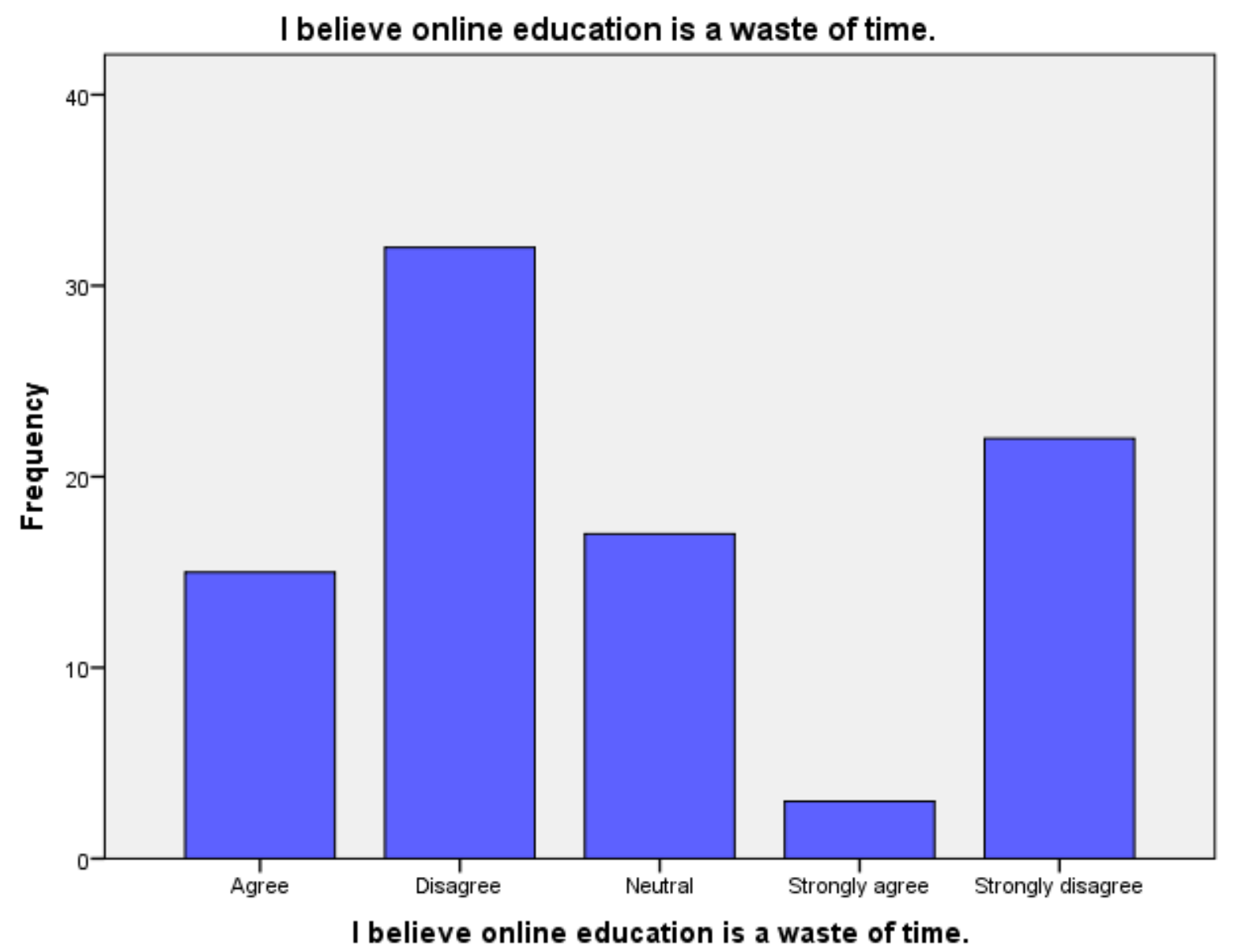

Fig.2: I believe online education is a waste of time

\section{CONCLUSION}

Slowly but surely, distant or online Learning is becoming the new standard in education. Practitioners and students are coming to terms with this new endeavor, working hard to find appropriate conditions to make it a timely success. However, digital learning is far from being able to replace conventional teaching. It would require extensive changes in logistics and attitudes. 
Currently,we may not beprimed yet to consider learning without face-to-face human presence. However, distant Learning is becoming a more practical alternative in various situations like pandemics, teachers' training, students' learning and so. With the rapid development of new technologies and educational trends, students will continue to normalize with e-learning.

\section{REFERENCES}

[1] Artino, A. R. (2008). Motivational beliefs and perceptions of instructional quality: Predicting satisfaction with online training. Journal of Computer Assisted Learning, 24(3), 260-270. Doi: 10.1111/j.1365-2729.2007.00258.x

[2] Bartram, B. (2010). Attitudes to modern foreign language learning: Insights from comparative education. New York: Continuum International Pub. Group.

[3] Berk, R. A. (1996). Student ratings of 10 strategies for using humor in college teaching. Journal on Excellence in College Teaching, 7(3), 71-92. Retrieved from https://www.researchgate.net /profile/RonaldBerk/publication/268058822_Student _Ratings_of_10_Strategies_for_Using_Humor_in_C ollege_Teaching/links/551c1afa0cf2909047b9ea30/St udent-Ratings-of-10-Strategies-for-Using-Humor-inCollege-Teaching.pdf

[4] Brophy, J. (1997). Motivating sudents to learn. New York: Routledge.

[5] Deci, E., \& Ryan, R. (1985). Intrinsic motivation and self-determination in human behavior. New York: Springer Science.

[6] Elkhayma, R. (2020). Affective factors in foreign language education: The role of anxiety. International Journal of English Literature and Social Sciences, 5(4), 853-860. Doi.org/10.22161/ijels.54

[7] Elkhayma, R. (2021). An experimental study of students' perceptions of classroom humour. International Journal of English Literature and Social Sciences, 6 (1), 443-451. doi.org/10.22161/ijels.61.59

[8] Ezzahid, E. (2020). L'enseignement à distance au Maroc: Perception des étudiants au période du confinement Covid-19 à partir d'une enquête nationale [Distance learning in Morocco : Students' perceptions during the Covid- 19 lockdown in a national study]. Retrieved from https://www.researchgate.net/publication/343404368

[9] Gardner, R., \& Lambert, W. (1959). Motivational variables in second-language acquisition. Canadian
Journal of Psychology, 13(4), 266-272. Retrieved from https://eric.ed.gov/?id=ED031968

[10] Gunawardena, C. N., \&McIsaac, M. S. (2004). Distance education. Handbook of Research on Educational Communications and Technology, 355395. Retrieved from https:// citeseerx.ist.psu.edu/viewdoc/download?doi=10.1.1.6 $42.8603 \&$ rep $=$ rep $1 \&$ type $=$ pdf

[11] Hantem, A. (2020). Les conditions de l'enseignement à distance pendant le confinement du Covid-19: Cas de l'enseignementsupérieur au Maroc [Conditions of distant learning during Covid-19: The case of higher education in Morocco]. Retrieved from https://hal.archives- ouvertes.fr/hal-02883214

[12] Johnson, G. (2008). The relative learning benefits of synchronous and asynchronous text- based discussion. British Journal of Educational Technology, 39(1), 166-169. Doi:10.1111/j.14678535.2007.00739.x

[13] Joseph, D. (2005). Hybrid design enables individualized learning experience. Distance Education Report, 9(5), 6-6.

[14] Keegan, D. (1995). Distance education technology for the new millennium compressed video teaching. Hagen: ZIFF. Retrieved from https://files.eric.ed.gov/fulltext/ED389931.pdf

[15] Keegan, D. (2000). Distance training: Taking stock at a time of change. New York: Routledge.

[16] Keller, J. M. (2008). First principles of motivation to learn and e-learning. Distant Education, 29(2), 175185. Doi: 10.1080/01587910802154970

[17] Taylor, J. C. (2001). Fifth generation distance education.20th World Conference on Open Learning and Distance Education, Dusseldorf, Germany. Retrieved from http://www.c31.unioldenburg.de/cde/media/readings/taylor01.pdf 